\title{
A INFLUÊNCIA DA MATA CILIAR NA QUALIDADE DAS ÁGUAS DO CÓRREGO BOM JARDIM - BRASILÂNDIA/MS: ESTUDOS INICIAIS.
}

\author{
Agnes Cássia Dias ${ }^{1}$
}

Arnildo Pott ${ }^{2}$

Resumo: O presente trabalho é um breve estudo sobre a influencia da mata ciliar na qualidade das águas do córrego Bom Jardim em Brasilândia/MS. Além de todos os outros índices de qualidade da água, a vegetação local também exerce um papel fundamental na qualidade das águas, tanto diretamente quanto indiretamente, o fundamento de estudar este parâmetro vem da necessidades de planejamentos para recuperação das matas ciliares do córrego em estudo, pois este apresenta quase todo o seu leito com áreas degradas e assoreadas pela falta da vegetação.

Palavras-Chave: mata ciliar, qualidade das águas, planejamento.

\footnotetext{
${ }^{1}$ Bacharel em Geografia pela Universidade Federal de Mato Grosso do Sul / Aluna no Programa de Pós Graduação em Geografia Campus de Três lagoas / agnescdias@gmail.com

${ }^{2}$ Professor Visitante Nacional Sênior, Bolsista da CAPES, no Programa de Pós-Graduação em Geografia Campus Três Lagoas / arnildo.pott@gmail.com
} 


\section{INTRODUÇÃO}

O planeta Terra é o único que possui água em seus três estados físicos (sólido, líquido e gasoso) e suas mudanças de estado são fundamentais e influenciam os processos biogeoquímicos nos ecossistemas terrestres e aquáticos (TUNDISI, 2003). Nestes termos a água se torna um elemento essencial para toda a sociedade e sua necessidade de desenvolvimento econômico, qualidade de vida e sustentabilidade. No entanto de toda a água do planeta apenas $3 \%$ é doce, desses $3 \%, 2,7 \%$ estão congelados nas calotas polares, restando apenas cerca de $1 \%$ de toda água do planeta, que são de captação (águas superficiais, lagos e rios) (CARVALHO, 2008).

Cientistas e Ambientalistas abordam cada vez mais a importância e a escassez da água para a sociedade, fazendo com que vários estudos sejam direcionados a qualidade, reaproveitamento e tratamento das águas, entre outros fatores importantes para o meio ambiente.

A qualidade da água dos rios é o resultado da interação entre o clima, a geologia, o solo e a vegetação da bacia hidrográfica. O papel desempenhado pela mata ciliar concorre tanto para diminuir a ocorrência do escoamento superficial, que pode causar erosão e arrastar nutrientes e sedimentos para os cursos d'água, quanto desempenhar um efeito de filtragem superficial e sub-superficial dos fluxos de águas para os canais (VEIGA, 2003).

A vegetação exerce influência direta na qualidade das águas, tanto aos arredores da bacia hidrográfica quanto as áreas que permeiam o corpo d'água. A mata ciliar, neste caso estudada, é a formação vegetal localizada nas margens dos córregos, lagos, represas e nascentes. Considerada pelo Código Florestal Federal como "área de preservação permanente", com diversas funções ambientais, devendo respeitar uma extensão específica de acordo com a largura do rio, lago, represa ou nascente.

O uso dessas áreas naturais para agricultura, pecuária, loteamentos e construções contribuem para redução da vegetação original, chegando em muitos casos na ausência da mata ciliar e com isso causando vários problemas como escassez da água pois a mata ciliar permite que a água infiltre nos lençóis freáticos, a erosão e assoreamento pois sem a mata ciliar o solo fica desprotegido e as chuvas acabam carregando todo material para o leito do córrego, a qualidade da água pois a mata ciliar 
reduz $\mathrm{o}$ assoreamento dos rios, deixa a água mais limpa facilitando a vida aquática. Em volta de todos esses e outros problemas a analise realizada nas matas ciliares são significantes e muito importantes para a preservação dos corpos d'águas ainda existentes.

O córrego Bom Jardim, possui 8 (oito) pontos de análises e coletas de amostras, e somente o ponto 1 possui mata ciliar e cercamento que protegem o canal do pisoteio de animais, intempéries da natureza e carreamento excessivo de sedimentos. Nos demais pontos não há presença de mata ciliar densa, ocasionando vários pontos de escorregamentos, assoreando as margens do canal principal e seus afluentes.

A bacia do Córrego Bom Jardim foi escolhida devido a sua localização no município de Brasilândia/MS (Figura 1), agravado pelos assentamentos desenvolvidos pela Companhia Energética de São Paulo - CESP, que não tiveram rigorosa fiscalização do cumprimento da legislação ambiental, esta se encontra submetida a acelerado ciclo erosivo, pondo em risco a sede do município, a cidade de Brasilândia, onde grandes ravinamentos e voçorocamentos avançam sobre vias públicas e edificações prediais domiciliares e públicas, além de assorear o lago da Usina Hidrelétrica de Porto Primavera, no rio Paraná. 


\section{Mapa de Articulação da Bacia Hidrográfica do córrego Bom Jardim}

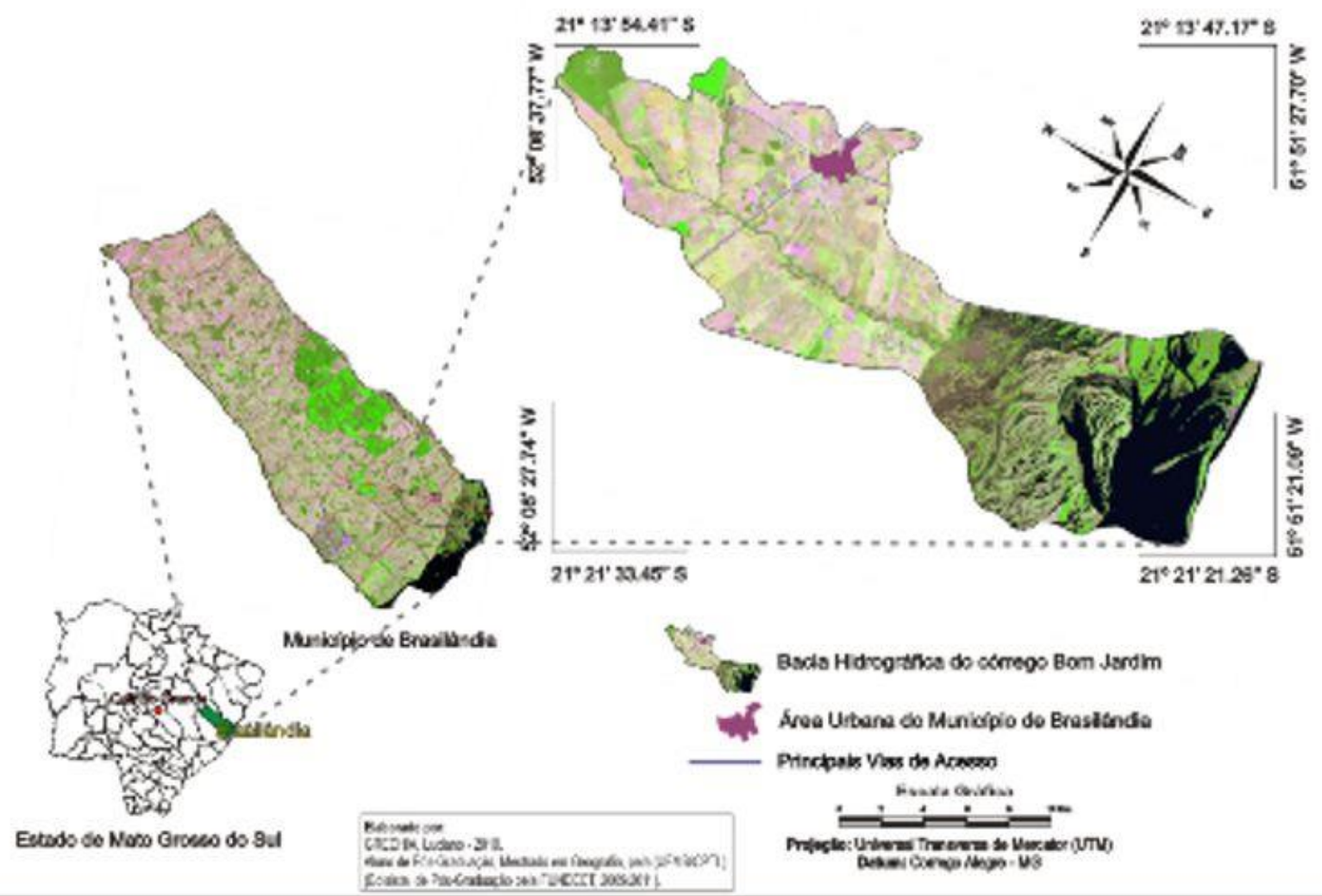

Figura 1: Mapa de localização da bacia.

FONTE: Luciano Grechia.

O presente estudo justifica-se então, pela necessidade de ampliar os conhecimentos sobre o a mata ciliar do córrego Bom Jardim, analisando os efeitos da ausência ou presença da mesma, relacionando à qualidade das águas, para que se possa predizer medidas básicas de planejamento e preservação não só da bacia hidrográfica como também da mata ciliar do córrego Bom Jardim.

\section{DESENCOLCIMENTO}

\subsection{DISCUSSÃO TEÓRICO METODOLÓGICA}


As abordagens teóricas metodológicas desse trabalho se apoiam em metodologias que norteiam a importância da análise da mata ciliar no papel da qualidade das águas, visando uma melhor compreensão do assunto e à representação com maior clareza e fidelidade da realidade da bacia do córrego Bom Jardim. A análise deste indicador de qualidade se faz necessária devido a várias formas de apropriação da terra e da visão de territorialidade da sociedade local sob o âmbito da visão holística, pois, segundo Milton Santos:

[...] só através de um ponto de vista holístico é que se pode compreender uma totalidade. Enquanto a compreensão de um aspecto é necessária à apreensão do todo, é inadmissível negligenciar qualquer uma das partes constituintes [...] (SANTOS, 1992, p.52).

Diante dessa perspectiva, torna-se indispensável a análise de cada indicador de qualidade da água, pois cada um deles será de grande utilidade para averiguar, quantificar a qualificar as águas do córrego Bom Jardim. Mata ciliar, segundo Fornari (2001) é "a vegetação que ocorre ao longo dos rios, exercendo influência direta no regime deles, servindo de proteção aos mananciais." Devido a isso se faz pertinente o estudo sobre esse indicativo de qualidade da água, uma vez que sua presença, quantidade e qualidade fazem com que o córrego, em estudo, apresente valores considerados relevantes.

O emprego de indicadores de qualidade de água consiste no uso de variáveis que se correlacionam com as alterações ocorridas na bacia, sejam estas de origens antrópicas ou naturais: "[...] o uso de índices de qualidade de água é uma tentativa que todo programa de monitoramento de águas prevê como forma de acompanhar, através de informações resumidas, a possível deterioração dos recursos hídricos ao longo da bacia hidrográfica ou ao longo do tempo." (PINTO, 2009).

Contudo a grande maioria dos indicadores ou índices de qualidade das águas são onerosos e morosos. Pinto et. al. (2010) salientam que o oxigênio dissolvido é um excelente indicador de qualidade das águas e que conjuntamente com parâmetros coadjuvantes de condutividade eletrica, $\mathrm{pH}$, turbidez e temperatura do ar e da água é possivel obter-se dados no campo a baixo custo e tempo real. 
O oxigênio dissolvido (O.D.) é um gás solúvel em água, com concentrações recomendáveis pelo CONAMA Resolução 357 de 17/03/05. Segundo Araújo et. al. (2004), o oxigênio dissolvido pode ser utilizado como indicador de qualidade das águas, pois a proliferação bacteriológica depende diretamente de suas concentrações, constituindo de metodologia de rápida análise, passível de realização no campo. É de fundamental importância na manutenção da vida aquática e da qualidade da água. TCHOBANOGLOUS e SCHROEDER (1985) afirmam que, devido à sua importância, o O.D. é amplamente utilizado como principal parâmetro da qualidade de água e serve para determinar o impacto de poluentes sobre corpos d'água, pois é um dos mais importantes fatores no desenvolvimento de qualquer planejamento na gestão de recursos hídricos.

O O.D. é o elemento principal no metabolismo dos microrganismos aeróbicos que habitam as águas naturais ou os reatores para tratamento biológico de esgotos, nas águas naturais, o oxigênio é indispensável também para os seres vivos, principalmente os peixes. O nível de O.D. em águas naturais é, com freqüência, uma indicação direta de qualidade, uma vez que as plantas aquáticas produzem oxigênio, enquanto microorganismos geralmente o consomem ao alimentarem-se de poluentes. Cabe salientar que águas poluídas são aquelas que apresentam baixa concentração de O.D., isso devido ao consumo de O.D. na decomposição e águas de boa qualidade apresentam concentrações elevadas de O.D. (MORAES, 2001).

A Condutividade expressa a capacidade de condução de corrente elétrica de sais dissolvidos e ionizados presentes na água, pode ser utilizada como parâmetro de avaliação de qualidade. Assim a condutividade também fornece uma boa indicação das modificações na composição da água, especialmente na sua concentração mineral, mas não fornece nenhuma indicação das quantidades relativas dos vários componentes.

A Turbidez é a alteração da penetração da luz provocada por partículas em suspensão, como bactérias, argilas e silte ou fontes de poluição que lançam materiais finos e outras substâncias na água. A presença dessas substâncias provoca a dispersão e a absorção da luz, dando à água aparência nebulosa, esteticamente indesejável e potencialmente perigosa (PINTO, 1998). Um alto valor de turbidez prejudica a condição estética da água, reduzindo a fotossíntese de vegetação enraizada submersa e algas, esse desenvolvimento reduzido pode suprimir a produtividade de peixes, além disso, afeta adversamente os usos domésticos, industriais e recreacional da água; estudos técnicos 
constatam o efeito de proteção física de microorganismos pelas partículas causadoras da turbidez, diminuindo a eficiência de tratamentos. A erosão das margens dos rios em estações chuvosas, o mau uso do solo, esgotos sanitários e diversos efluentes industriais, são exemplos de fenômenos que resultam em aumento da turbidez das águas causando problemas ao ambiente (água, ar e solo).

$\mathrm{O}$ pH é a medida de concentração de íons $\mathrm{H}+$ presentes na solução, é umas das determinações de qualidade de água mais freqüentemente executadas, apresentando a acidez ou a basicidade das águas, que podem ter origens em fatores naturais do terreno ou resultantes de poluentes dissolvidos na água. A análise do $\mathrm{pH}$ será feita através do método eletrométrico (CETESB, 1987).

\subsection{PROCESSOS METODOLÓGICOS}

Para a realização e a execução das análises, este trabalho se dividi em três etapas fundamentais e serão utilizados os seguintes materiais nas etapas descritas:

Delimitação da área de estudo: Nesta etapa foi definida a área de estudo do córrego Bom Jardim, por meio das cartas topográficas de Brasilândia (folha SF. 22.V.D.I) na escala de 1:100.000 e delimitar toda a área da bacia hidrográfica. Foram utilizados também fotos aéreas e imagens de satélite para atualização de estradas e uso e ocupação da terra.

Análises de campo: foram realizadas visitas no local, para as fotografias da vegetação e dos aspectos físicos do canal principal e afluentes, para isso foi utilizada uma câmera digital. Para as coletas de amostras de água foram utilizados frascos de $500 \mathrm{ml}$, que foram mergulhados da superfície até o fundo do canal sem que o frasco encoste no leito. Durante a coleta foi levado em consideração a estação do ano (primavera, verão, outono e inverno), sendo uma coleta por estação, sendo que em cada coleta foi feita em 8 pontos já pré definidos e uma coleta por ponto, totalizando 8 frascos de amostragem por estação do ano. Nas estações, pré-definidas, também foram feitas coleta de amostras para alguns testes como $\mathrm{pH}$, condutividade elétrica, temperatura do ar e da água, turbidez e oxigênio dissolvido, que foram todos coletados, analisados e comparados entre as 
estações de coleta, levando em consideração a presença ou não da vegetação. Para essas medições foram utilizados os seguintes materiais, descritos na Tabela 1:

Tabela 1 - Equipamentos utilizados para coletas de amostras das águas do córrego Bom Jardim, no município de Brasilândia, MS.

\begin{tabular}{|l|l|}
\hline Parâmetros & Equipamentos \\
\hline Oxigênio Dissolvido - OD & Lutron DO - 5510 \\
\hline Condutividade - CE & Tecnopron MCA - 150 \\
\hline Turbidez & Tecnopron TB 1000 \\
\hline pH & Phtek pH - 100 \\
\hline Temperatura & Lutron DO - 5510 \\
\hline Velocidade & Molinete \\
\hline
\end{tabular}

Em agosto de 2012 foram feitos registros da qualidade da água e da vegetação local. Os dados referidos á qualidade da água são:

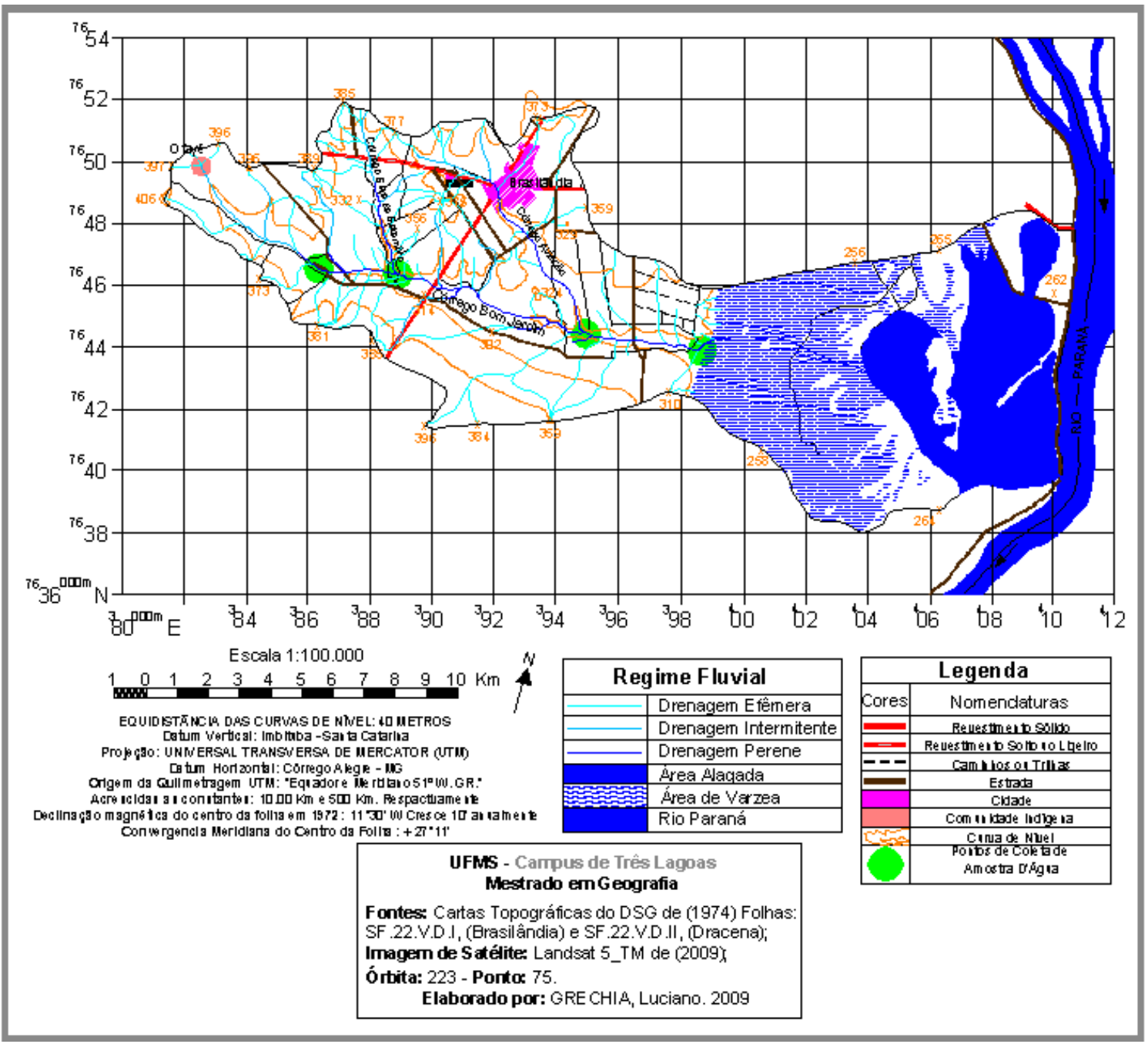


Figura 2; Localização dos pontos de Coleta.

FONTE: Luciano Grechia.

Tabela 2: Dados de agosto 2012.

\begin{tabular}{|c|c|c|c|c|c|c|c|c|}
\hline Pontos & Horário & $\begin{array}{c}\text { C. E. } \\
(\mathbf{u m})\end{array}$ & $\begin{array}{c}\text { O. D. } \\
(\mathbf{m g} / \mathbf{l})\end{array}$ & $\begin{array}{c}\text { Velocidade } \\
(\mathbf{m} / \mathbf{s})\end{array}$ & $\begin{array}{c}\text { Temp. Ar } \\
\left({ }^{\circ} \mathbf{C}\right)\end{array}$ & $\begin{array}{c}\text { Temp. H2O } \\
\left({ }^{\circ} \mathbf{C}\right)\end{array}$ & Ph & $\begin{array}{c}\text { Turbidez } \\
\text { NTU }\end{array}$ \\
\hline 1 & $13: 06$ & 14,00 & 7,90 & 0,21 & 29,2 & 24,5 & 7,40 & 17,20 \\
\hline 2 & $14: 08$ & 21,00 & 4,90 & 0,95 & 32,9 & 26,8 & 7,60 & 32,70 \\
\hline 3 & $14: 30$ & 20,00 & 8,40 & 0,39 & 29,0 & 24,2 & 8,10 & 13,30 \\
\hline 4 & $14: 49$ & 20,00 & 8,40 & 0,43 & 24,3 & 23,0 & 7,10 & 41,90 \\
\hline 5 & $10: 26$ & 23,00 & 5,80 & 1,15 & 30,0 & 28,4 & 7,90 & 11,30 \\
\hline 6 & $11: 12$ & 61,00 & 8,40 & 0,58 & 29,5 & 26,3 & 7,00 & 16,30 \\
\hline 7 & $10: 50$ & 22,00 & 6,00 & 1,39 & 30,6 & 26,2 & 7,90 & 11,70 \\
\hline 8 & $09: 29$ & 48,00 & 6,80 & 0,25 & 23,7 & 22,8 & 7,80 & 9,40 \\
\hline
\end{tabular}

FONTE: Gustavo de Oliveira, 2012

Nota-se que os pontos 1, 3, 5, 7 e 8 possuem os menores dados de turbidez, porem o que deve ser levado em consideração é sua vegetação. No ponto 1 há uma densa mata ciliar porém a presença constante de animais é grande o que influencia muito no carregamento de cedimentos para dentro do leito do córrego. No ponto 8 também há uma grande mata ciliar e há presença de cercas ao redor do córrego, dificultando assim que oa animais tenham acesso ao córrego.

Os dados de temperado da água também são muito importantes, uma vez que a falta da vegetação acarreta na incidência direto dos raios solares, alterando assim a sus temperatura e influenciando em outros aspectos físicos, químicos e biológicos do córrego Bom Jardim.

$\mathrm{Na}$ coleta de amostras de vegetação, é feitas parcelas (ou transcetos) de $5 \mathrm{~m}$ por $10 \mathrm{~m}$ ao longo do ponto de coleta de águas e dentro dessa delimitação é medido a circunferência dos caules (mínimo de $5 \mathrm{~cm}$, critério estabelecido devido ao tipo de vegetação que mantém caules muito finos em relação a outras vegetações) e anotadas as espécies.

Foram feitas 3 parcelas no ponto de coleta 1, gerando as seguintes dados vegetais: 
Tabela 2: Dados coletados no córrego Bom Jardim, Parcela 1, Ponto 1.

\begin{tabular}{|c|l|c|c|}
\hline & \multicolumn{1}{|c|}{ Córrego Bom Jardim } & \multicolumn{2}{c|}{ Parcela 5mX10m } \\
\hline & \multicolumn{1}{|c|}{ Ponto 1 - Parcela 1 } & \multicolumn{1}{c|}{ Circunferência mínima de 5cm } \\
\hline & \multicolumn{1}{|c|}{ NOME } & DIÂMETRO & ALTURA (estimada) \\
\hline 1 & ALIBETIA EDULIS & $16 \mathrm{~cm}$ & $3,5 \mathrm{~m}$ \\
\hline 2 & ALIBETIA EDULIS & $15 \mathrm{~cm}$ & $4.0 \mathrm{~m}$ \\
\hline 3 & ALIBETIA EDULIS & $15 \mathrm{~cm}$ & $4,5 \mathrm{~m}$ \\
\hline 4 & MACAERA RÁDULA & $7 \mathrm{~cm}$ & $2,1 \mathrm{~m}$ \\
\hline 5 & MACAERA RÁDULA & $10 \mathrm{~cm}$ & $3,5 \mathrm{~m}$ \\
\hline 6 & MACAERA RÁDULA & $5 \mathrm{~cm}$ & $1,5 \mathrm{~m}$ \\
\hline 7 & MACAERA RÁDULA & $12 \mathrm{~cm}$ & $3,5 \mathrm{~m}$ \\
\hline 8 & MACAERA RÁDULA & $6 \mathrm{~cm}+5 \mathrm{~cm}$ & $2,0 \mathrm{~m}$ \\
\hline 9 & MACAERA RÁDULA (morta) & $10 \mathrm{~cm}$ & $2,5 \mathrm{~m}$ \\
\hline 10 & MAPRONIA & $12 \mathrm{~cm}$ & $3,0 \mathrm{~m}$ \\
\hline 11 & MAPRONIA & $15 \mathrm{~cm}$ & $5,0 \mathrm{~m}$ \\
\hline 12 & MAPRONIA & $10 \mathrm{~cm}$ & $3,5 \mathrm{~m}$ \\
\hline 13 & MAPRONIA & $13 \mathrm{~cm}$ & $3,5 \mathrm{~m}$ \\
\hline 14 & MAPRONIA & $14 \mathrm{~cm}$ & $4,0 \mathrm{~m}$ \\
\hline 15 & TAPIRIRA GUIANENSES (PAU POMBO) & $26 \mathrm{~cm}$ & $5,5 \mathrm{~m}$ \\
\hline 16 & TAPIRIRA GUIANENSES (PAU POMBO) & $40 \mathrm{~cm}$ & $5,5 \mathrm{~m}$ \\
\hline 17 & TAPIRIRA GUIANENSES (PAU POMBO) & $8 \mathrm{~cm}$ & $3,3 \mathrm{~m}$ \\
\hline 18 & TAPIRIRA GUIANENSES (PAU POMBO) & $8 \mathrm{~cm}+17 \mathrm{~cm}$ & $5,5 \mathrm{~m}$ \\
\hline 19 & TERMINALIA GLABRESSEM & $20 \mathrm{~cm}$ & $4,0 \mathrm{~m}$ \\
\hline 20 & XYLOPIA AROMÁTICA (PIMENTA DE MACACO) & $15 \mathrm{~cm}$ & $4,2 \mathrm{~m}$ \\
\hline
\end{tabular}

FONTE: Agnes Dias, 2012.

A segunda coluna representa o nome da espécie analisada, a terceira coluna específica o diâmetros dos caules encontrados, nota-se que alguns possuem 2 medidas, neste caso a espécie possui dois caules, e por fim a quarta coluna representa a altura da espécie em questão. 
Tabela 3: Dados coletados no córrego Bom Jardim, Parcela 2, Ponto 1.

\begin{tabular}{|c|l|c|c|}
\hline & \multicolumn{1}{|c|}{ Córrego Bom Jardim } & \multicolumn{2}{c|}{ Parcela 5mX10m } \\
\hline & \multicolumn{1}{|c|}{ Ponto 1 - Parcela 2 } & \multicolumn{2}{c|}{ Circunferência mínima de 5cm } \\
\hline & \multicolumn{1}{|c|}{ NOME } & DIÂMETRO & $\begin{array}{c}\text { ALTURA } \\
\text { (estimada) }\end{array}$ \\
\hline 1 & DENDROPANAX CUNEATUM & $5 \mathrm{~cm}$ & $2,2 \mathrm{~m}$ \\
\hline 2 & FERDINANDUZA & $5 \mathrm{~cm}$ & $2,0 \mathrm{~m}$ \\
\hline 3 & FERDINANDUZA & $8 \mathrm{~cm}$ & $2,7 \mathrm{~m}$ \\
\hline 4 & FERDINANDUZA (morta) & $7 \mathrm{~cm}+7 \mathrm{~cm}$ & $2,2 \mathrm{~m}$ \\
\hline 5 & MACAERA RÁDULA & $8 \mathrm{~cm}$ & $2,5 \mathrm{~m}$ \\
\hline 6 & MACAERA RÁDULA & $13 \mathrm{~cm}$ & $3,1 \mathrm{~m}$ \\
\hline 7 & MACAERA RÁDULA & $7 \mathrm{~cm}+9 \mathrm{~cm}$ & $2,9 \mathrm{~m}$ \\
\hline 8 & MACAERA RÁDULA & $6 \mathrm{~cm}+5 \mathrm{~cm}+11 \mathrm{~cm}+9 \mathrm{~cm}$ & $4,0 \mathrm{~m}$ \\
\hline 9 & MACAERA RÁDULA & $7 \mathrm{~cm}+9 \mathrm{~cm}$ & $2,5 \mathrm{~m}$ \\
\hline 10 & MACAERA RÁDULA (morta) & $6 \mathrm{~cm}+5 \mathrm{~cm}$ & $1,6 \mathrm{~m}$ \\
\hline 11 & MICONIA CHAMISSOIS & $6 \mathrm{~cm}+6 \mathrm{~cm}$ & $2,2 \mathrm{~m}$ \\
\hline 12 & MICONIA CHAMISSOIS & $6 \mathrm{~cm}$ & $2,0 \mathrm{~m}$ \\
\hline 13 & MICONIA CHAMISSOIS & $6 \mathrm{~cm}$ & $2,0 \mathrm{~m}$ \\
\hline 14 & MYRCIA & $9 \mathrm{~cm}$ & $2,5 \mathrm{~m}$ \\
\hline 15 & MYRCIA & $7 \mathrm{~cm}$ & $2,5 \mathrm{~m}$ \\
\hline 16 & MYRCIA & $7 \mathrm{~cm}$ & $1,7 \mathrm{~m}$ \\
\hline 17 & TAPIRIRA GUIANENSES (PAU POMBO) & $15 \mathrm{~cm}+7 \mathrm{~cm}$ & $3,8 \mathrm{~m}$ \\
\hline 18 & TAPIRIRA GUIANENSES (PAU POMBO) & $42 \mathrm{~cm}$ & $6,0 \mathrm{~m}$ \\
\hline 19 & TAPIRIRA GUIANENSES (PAU POMBO) & $33 \mathrm{~cm}$ & $6,0 \mathrm{~m}$ \\
\hline 20 & TAPIRIRA GUIANENSES (PAU POMBO) & $34 \mathrm{~cm}$ & $6,0 \mathrm{~m}$ \\
\hline 21 & TAPIRIRA GUIANENSES (PAU POMBO) & $42 \mathrm{~cm}$ & $6,0 \mathrm{~m}$ \\
\hline
\end{tabular}

Fonte: Agnes Dias, 2012.

Nesta parcela houve predominio de espécies mais baixas e várias outras plantas que não entraram no padrão de $5 \mathrm{~cm}$ de diâmetro do caule. A vegetação predominante do local é o cerrado, caracterizado por plantas baixas, arbustivas, retorcidas e espassadas. O grande volume de vegetação encontra-se apenas nesse ponto de observação devido a uma Area de Preservação Permanente e também a presença da nascente do córrego em estudo. A mata ciliar do ponto 1, se torna bem densa apenas nas margens. Em em uma das suas margens a presença do cultivo de eucalipto é preocupante, uma vez que não há cercamento nenhum impedindo a passagem de pessoas e animais, já na outra margem a presença de pasto e animais também é notávelmente grande. 
Tabela 4: Dados coletados no córrego Bom Jardim, Parcela 3, Ponto 1.

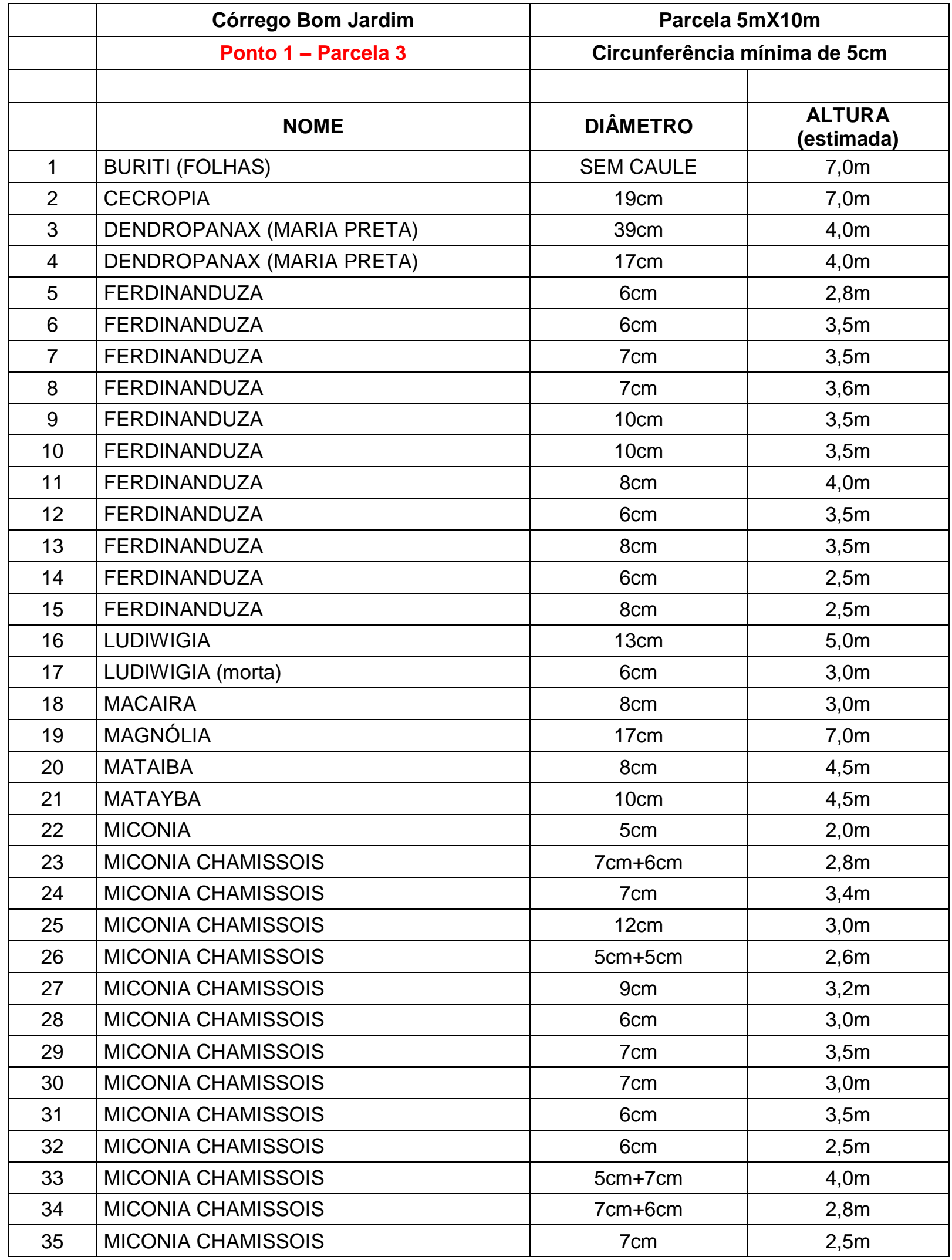




\begin{tabular}{|c|c|c|c|}
\hline 36 & MICONIA CHAMISSOIS (morta) & $7 \mathrm{~cm}+5 \mathrm{~cm}$ & $2,0 \mathrm{~m}$ \\
\hline 37 & MYRCIA & $6 \mathrm{~cm}$ & $3,0 \mathrm{~m}$ \\
\hline 38 & MYRCIA & $6 \mathrm{~cm}+6 \mathrm{~cm}$ & $3,0 \mathrm{~m}$ \\
\hline 39 & MYRCIA & $5 \mathrm{~cm}$ & $3,0 \mathrm{~m}$ \\
\hline 40 & MYRCIA & $8 \mathrm{~cm}$ & $3,0 \mathrm{~m}$ \\
\hline 41 & MYRCIA & $7 \mathrm{~cm}$ & $3,0 \mathrm{~m}$ \\
\hline 42 & MYRCIA & $9 \mathrm{~cm}$ & $3,0 \mathrm{~m}$ \\
\hline 43 & MYRCIA & $15 \mathrm{~cm}$ & $4,5 \mathrm{~m}$ \\
\hline 44 & MYRCIA & $10 \mathrm{~cm}$ & $4,5 \mathrm{~m}$ \\
\hline 45 & NECTRANDA (CANELA DO BREJO) & $5 \mathrm{~cm}+6 \mathrm{~cm}$ & $1,9 m$ \\
\hline 46 & NECTRANDA (CANELA DO BREJO) & $6 \mathrm{~cm}$ & $1,7 \mathrm{~m}$ \\
\hline 47 & NECTRANDA (CANELA DO BREJO) & $6 \mathrm{~cm}+6 \mathrm{~cm}$ & $2,2 m$ \\
\hline 48 & NECTRANDA (CANELA DO BREJO) & $7 \mathrm{~cm}+6 \mathrm{~cm}$ & $2,6 m$ \\
\hline 49 & NECTRANDA (CANELA DO BREJO) & $5 \mathrm{~cm}$ & $2,1 \mathrm{~m}$ \\
\hline 50 & NECTRANDA (CANELA DO BREJO) & $16 \mathrm{~cm}$ & $7,0 \mathrm{~m}$ \\
\hline 51 & NECTRANDA (CANELA DO BREJO) & $10 \mathrm{~cm}$ & $3,0 \mathrm{~m}$ \\
\hline 52 & NECTRANDA (CANELA DO BREJO) & $8 \mathrm{~cm}$ & $3,2 m$ \\
\hline 53 & NECTRANDA (CANELA DO BREJO) & $7 \mathrm{~cm}$ & $3,2 m$ \\
\hline 54 & NECTRANDA (CANELA DO BREJO) & $14 \mathrm{~cm}$ & - \\
\hline 55 & NECTRANDA (CANELA DO BREJO) & $16 \mathrm{~cm}+13 \mathrm{~cm}$ & $5,5 \mathrm{~m}$ \\
\hline 56 & NECTRANDA (CANELA DO BREJO) & $7 \mathrm{~cm}+6 \mathrm{~cm}$ & $2,5 \mathrm{~m}$ \\
\hline 57 & NECTRANDA (CANELA DO BREJO) & $8 \mathrm{~cm}$ & $4,0 \mathrm{~m}$ \\
\hline 58 & NECTRANDA (CANELA DO BREJO) & $11 \mathrm{~cm}$ & $5,0 \mathrm{~m}$ \\
\hline 59 & NECTRANDA (CANELA DO BREJO) & $8 \mathrm{~cm}$ & $3,5 \mathrm{~m}$ \\
\hline 60 & NECTRANDA (CANELA DO BREJO) & $11 \mathrm{~cm}$ & $3,7 \mathrm{~m}$ \\
\hline 61 & NECTRANDA (CANELA DO BREJO) & $7 \mathrm{~cm}$ & $3,5 \mathrm{~m}$ \\
\hline 62 & NECTRANDA (CANELA DO BREJO) & $6 \mathrm{~cm}$ & $2,0 \mathrm{~m}$ \\
\hline 63 & NECTRANDA (CANELA DO BREJO) & $11 \mathrm{~cm}$ & $3,5 \mathrm{~m}$ \\
\hline 64 & OURÁTEA & $5 \mathrm{~cm}+5 \mathrm{~cm}$ & $3,0 \mathrm{~m}$ \\
\hline 65 & OURÁTEA & $9 \mathrm{~cm}+9 \mathrm{~cm}$ & $4,2 m$ \\
\hline 66 & RUDGEA (CONGONHA) & $8 \mathrm{~cm}$ & $2,5 \mathrm{~m}$ \\
\hline 67 & RUDGEA (CONGONHA) & $11 \mathrm{~cm}$ & $4,3 m$ \\
\hline 68 & RUDGEA (CONGONHA) & $14 \mathrm{~cm}+11 \mathrm{~cm}$ & $3,0 \mathrm{~m}$ \\
\hline 69 & SAPION & $24 \mathrm{~cm}$ & $4,8 m$ \\
\hline 70 & TAPIRIRA GUIANENSES (PAU POMBO) & $38 \mathrm{~cm}$ & $7,0 \mathrm{~m}$ \\
\hline
\end{tabular}

FONTE: Agnes Dias, 2012.

Nesta parcela houve a grande presença da espécia Nectranda nitidula, popularmente conhecida como canela do brejo caracterizada por plantas de altura média entre 4-8 m, podendo apresentar-se também como simples arbusto. Copa geralmente irregular e rala, com ramos novos levemente angulados nas extremidades. Folhas 


\section{Then Fórum Ambiental \\ da Alta Paulista

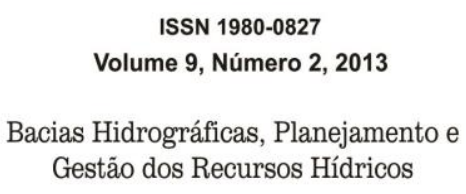

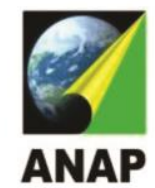

alternas, simples, brilhantes, cariáceas, glabrescentes, em ambas as faces, de margens inteiras e planas, de $6-12 \mathrm{~cm}$ de comprimento por $2-5 \mathrm{~cm}$ de largura, com flores suavemente perfumadas. Fruto baga elipsoide. Ocorrência nos estados da Bahia até o Paraná, em matas ciliares de regiões de cerrados e em matas secundárias (capoeiras), em altitudes compreendidas entre 800 e $1300 \mathrm{~m}$.

A importancia do registro das espécies vegetais se dá a preservação das margens do córrego Bom Jardim e um planejamento de recuperação das margens que estão assoreadas, não só com plantas de fácil crescimento e rápida recuperação como por exemplo a Bambusa arundinacea (bambu) como também um plano de recuperação com plantas nativas do local, para a preservação das características da região sem agredir o processo e equilíbrio natural natural do córrego.

O processo de recuperação com plantas nativas é mais demorado e requer maior atenção e estudo da vegetação local. No cerrado o melhor planejamento se daria pelas espécies que produzem frutos pois assim a sua disseminação seria maior através da fauna no local, proporcionando uma interação melhor entre o meio vegetal e animal.

Análises laboratoriais: Analisar-se-á competência fluvial do córrego, serão realizadas pesagens dos filtros com e sem sedimentos. A competência fluvial nada mais é do que a quantidade de sedimentos carregados pelo córrego durante um período, neste caso, após a realização dos cálculos, a competência fluvial se dará em toneladas por estação (verão, outono, inverno e primavera), logo em toneladas por ano, que serão analisadas de acordo com os locais de coletas, levando em consideração a mata ciliar e as condições que ela apresenta.

Após a conclusão das três etapas, serão analisados todos os dados e informações obtidas para a discussão dos resultados e a conclusão.

\section{CONCLUSÃO}

De acordo com os estudos realizados, foi possível observar a grande fragilidade da área, devido a vários fatores como a reduzida cobertura vegetal, em especial ciliar, a precária utilização de práticas conservacionistas empregadas no uso, 
ocupação e manejo da terra, produzidas pela ação antrópica associadas às fragilidades ambientais naturais de seus solos friáveis e pouco coesos, derivados do arenito do grupo Bauru, que pesar da baixa declividade, entre 0 a 3\%, influem na elevada competência fluvial de transportes de sedimentos. Que além, de assorearem o médio e baixo curso da bacia do Bom Jardim e de sua foz no rio Paraná, no lago da represa de Porto Primavera, compromete a qualidade de suas águas superficiais e de vida da população da cidade de Brasilândia cortada por seu afluente, da biodiversidade da Reserva do Patrimônio Particular Natural - RPPN da Cisalpina e da aldeia indígena Ofayé Xavante.

A grande relação da qualidade da água com a mata ciliar (APP) é notavel em toda a pesquisa. Observando os pontos de coleta foi possivel analisar varios fatores que contribuem para a qualidade da água. A presença da mata ciliar é muito importante porem a sua manutenção a cercamento contribuem para uma APP que possa preservar todas as características químicas, físicas e biológicas do córrego.

Com as coletas realizadas, foi possível observar a quantidade de sedimentos carreados durante o curso do córrego, a temperatura e comparar com a presença ou ausencia da mata ciliar. Com esses dados foi possível analisar a importância da presença da vegetação e por isso far-se-á esta pesquisa, para que se possa engrenar planejamentos de recuperação de toda mata ausente no córrego Bom Jardim, de forma que o córrego possa se recuperar e manter uma área de manancial protegida dos assoreamentos animais, antrópicos e naturais. 


\section{REFERÊNCIAS}

BRASIL Conselho Nacional do Meio Ambiente - CONAMA Resolução 357/2005, Enquadramento do Corpos Hídricos Superficiais no Brasil.. Governo Federal, Brasilia. Publicada no DOU n 53, de 18 de março de 2005, Seção 1, páginas 58-63.

CARVALHO, N. de O. Hidrossedimentologia prática. $2^{\text {a }}$ ed., ver., atual. ampliada - Rio de Janeiro: Interciência, p. 4 a 11 e 73 a 80. 2008

CESP Plano de Manejo da Reserva Cisalpina. Companhia Energética de São Paulo: Relatório. São Paulo, 2007: 234p.

CETESB. Companhia de Tecnologia de Saneamento Básico. Guia de coleta e preservação de amostras de água. São Paulo, 1987: 150p. (Séries guias)

FORNARI, Ernani. Dicionário Prático de Ecologia. São Paulo: Editora Aquariana, 2001. $293 p$.

GRECHIA, L.; Dinâmica Geomorfologica da Bacia Hidrográfica do córrego Bom Jardim, Brasilândia/MS. Dissertação de mestrado - Fundação Universidade Federal de Mato Grosso do Sul, Brasil. 2011.

PINTO, A. RODRIGUES, A. C. Enquadramento das águas superficiais das lagoas urbanas de Três Lagoas/MS. $4^{\circ}$ Encontro Nacional de Grupos PET Geografia "Os paradigmas da Geografia (re) pensando o território e o ambiente no ensino, pesquisa e extensão". 27 a 30 de outubro. Três Lagoas - MS. 2009.

PINTO, André Luiz. Saneamento Básico e suas Implicações na Qualidade das Águas Subterrâneas da Cidade de Anastácio (MS). 1998.175p. Tese (Doutorado e Geociências) - Universidade Estadual Paulista/Instituto de Geociências e Ciências Exatas, Rio Claro, 1998.

TUNDISI, José Galizia. Recursos Hídricos. Instituto Internacional de Ecologia. São Carlos - SP.

VEIGA, M.P.; MARTINS, S.S.; TORMENA, C.A.; SILVA, O.H. Influência da mata ciliar sobe a qualidade da água do Ribeirão Aurora, no município de Astorga, Paraná. Arq. Ciên. Vet. Zool. UNIPAR, 6(2): p. 149-152, 2003. 